\title{
Takedown and Today's Academic Digital Library
}

\author{
BRIANNA L. SCHOFIELD \& JENNIFER M. URBAN*
}

\section{CONTENTS}

I. INTRODUCTION .126

II. DMCA TAKEDOWN REQUESTS: CURRENTLY RARE, BUT UNSETTLED

III. NON-DMCA TAKEDOWN REQUESTS ......................................... 141

A. Requests based in claims other than copyright...................143

B. Copyright-based requests that fall outside the DMCA's

\begin{abstract}
* Brianna L. Schofield is the Executive Director of Authors Alliance and former Clinical Teaching Fellow at the Samuelson Law, Technology \& Public Policy Clinic at the University of California, Berkeley School of Law. Jennifer M. Urban is a Clinical Professor of Law at the University of California, Berkeley School of Law and Director of the Samuelson Law, Technology \& Public Policy Clinic. This paper is part of the Berkeley Digital Library Copyright Project and the Takedown Project. The authors are grateful for funding from the Alfred P. Sloan Foundation. Neither our funder nor any of our study respondents directed our approach or reviewed any methods, data, results, or reporting before public release. We thank the survey respondents and interview subjects, who generously shared their time and expertise; Kristoff Grospe and Joe Karaganis for helping to develop the survey; and Kenneth Crews, David Hansen, and Carl Johnson for helpful feedback on the survey instrument. We are grateful to David Hansen, Laura Quilter, Guy Rub, Mike Wolfe, and participants in The Future of Libraries in the Digital Age conference for thoughtful comments on drafts. Mistakes are ours alone.
\end{abstract}

The Berkeley Digital Library Copyright Project is an effort organized by Berkeley Law professors Pamela Samuelson, Jennifer M. Urban, and Jason Schultz (now at New York University School of Law). The Project aims to investigate copyright obstacles facing libraries and other like-minded organizations in their efforts to realize the full potential of present and future digital library initiatives. More information can be found on the project's website,

https://www.law.berkeley.edu/clinics/samuelson-law-technology-public-policy-clinic/digitallibrary-copyright-project/. The Takedown Project is a collaborative effort led by Urban and Joe Karaganis to develop a global network of researchers studying notice and takedown procedures, in order to advance understanding of how these procedures resolve copyright and other conflicts and how they mediate freedom of expression online. More information can be found on the project's website, https://takedownproject.org. 
IV. DISCUSSION AND RECOMMENDATIONS ...................................146

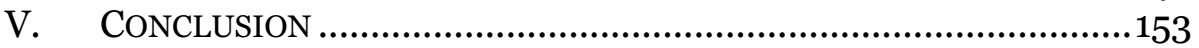

APPENDIX A: NOTICE AND TAKEDOWN LIBRARY SURVEY .......................155

\begin{abstract}
Fueled by recent public and private efforts to improve access to scholarly works, academic libraries and archives $^{1}$ are increasingly digitizing their special collections and creating online repositories for scholarly works. This enhanced online presence has increased libraries' exposure to takedown requests from rightsholders and other concerned parties. Using survey questions and interviews, we examined academic libraries' interaction with both Digital Millennium Copyright Act ("DMCA") and non-DMCA takedown notices. We found that academic libraries most commonly receive non-DMCA takedown requests that are based on non-copyright issues (such as privacy) or that target materials the library itself has placed online. In general, libraries have well-developed norms and practices in place to manage these types of requests to remove material. We also found, however, that libraries have not yet developed norms and practices for addressing formal DMCA notices. Remedying this may be helpful: while DMCA notices directed to libraries have historically been rare, this may be changing as libraries increasingly host open access repositories. We discuss why norms and practices for DMCA notices have not yet developed, and suggest steps libraries, publishers, and authors can take to best manage copyright conflicts while supporting libraries' missions to preserve and provide access to knowledge.
\end{abstract}

\title{
I. INTRODUCTION
}

In recent years, both academic libraries and archives have increasingly used digital means to preserve materials and provide access to users, allowing them to serve more diverse, and much more far-flung, populations. For example, libraries and archives are increasingly digitizing collections with unique or rare material that otherwise has limited circulation in order to improve long-term

\footnotetext{
${ }^{1}$ Most of our respondents self-identified as librarians, and, as such, this paper generally refers to "librarians" and their experiences. Several respondents had experience with both libraries and archives; we reflect our respondents' use of "librarians" and "archivists" where they made this distinction.
} 
preservation and expand access to cultural heritage. ${ }^{2}$ The growth of online scholarship repositories and sharing sites, where academic authors post papers for wide access, is another central development. This evolution of the dissemination of academic works from collections held solely within library and archive premises to open digital forms is widely heralded as increasing access to academic knowledge and fueling research. And the phenomenon extends beyond academic institutions: as readers connect more with books through e-books ${ }^{3}$ and other digital reading formats, public libraries will also grow their digital offerings. Further, some academic and other libraries-a flagship example is the Digital Public Library of America ("DPLA")-are taking on aggregator roles in which they provide "portal" type access to materials at other institutions through linking to the materials. ${ }^{4}$ Overall, online access to library and archive materials is growing and poised to grow further.

At the same time, libraries and members of the public have expressed frustration with publishers' slowness to adapt their business models to include open online access. This has prompted recent and growing efforts to create wider availability of scholarship through policies that promote public or open access. ${ }^{5}$ Proponents argue that these policies will improve access to knowledge by both citizens and other researchers, thus increasing the state of knowledge and the return on investment for publicly funded research. Academic

\footnotetext{
2 According to one report, 97 percent of 169 research libraries surveyed in 2009-10 had completed one or more digitization project and/or had an active digitization program for special collections materials. JACKIE M. DOOLEY \& KATHERINE LUCE, TAKING OUR PULSE: THE OCLC RESEARCH SURVEY OF SPECIAL COLLECTIONS AND ARCHIVES 17, 54 (2010).
}

3 The e-book market accounted for 23 percent of publisher net revenue in 2012, up from 17 percent in 2011 and 1 percent in 2008. Jeremy Greenfield, Ebooks Account for 23\% of Publisher Revenue in 2012, Even as Growth Levels, DigITAL BOOK WORLD (Apr. 11, 2013), http://www.digitalbookworld.com/2013/ebooks-account-for-23-of-publisher-revenue-in2012-even-as-growth-levels/ [https://perma.cc/AXD3-J7D4].

4 The Digital Public Library of America offers access to more than two million open ebooks. Bookshelf, DigiTAL PUB. LIBR. OF AM., https://dp.la/info/ [https://perma.cc/NK9J$\left.\mathrm{H}_{4} \mathrm{UU}\right]$.

5 Definitions of and distinctions between open access and public access are debated and, as such, unsettled. Public access policies typically require that research at least be made freely available online, whereas open access policies typically require that the work be available "digital[ly], online, free of charge, and free of most copyright and licensing restrictions." See, e.g., Peter Suber, Open Access Overview, EARLHAM COLL., http://legacy.earlham.edu/ peters/fos/overview.htm [https://perma.cc/39QX-7R7G]. 
libraries and their affiliated institutions have played a large role in these efforts, increasingly developing and implementing open access policies and committing to the "immediate and barrier-free online dissemination of scholarly research." 6

These efforts are further supported and fueled by the recent growth in policies by both federal government agencies and private funders mandating public or open access to funded research. In 2008, the United States federal government required the National Institutes of Health ("NIH") to implement a public access policy for published results of NIH-funded research. The policy requires that peerreviewed manuscripts be made available to the public free of charge online, no later than a year after publication.7 In 2013, the White House's Office of Science and Technology Policy issued a memorandum extending a similar policy to research funded by any federal agencies with a research budget over $\$ 100$ million. ${ }^{8}$ With the White House's move, almost twenty agencies, including those most active in research, are now covered by public access requirements. ${ }^{9}$

\footnotetext{
${ }^{6}$ This is one of the key principles of the Coalition of Open Access Policy Institutions (COAPI). SPARC*, COAPI PRINCIPLES, http://www.sparc.arl.org/sites/default/files/COAPIPrinciples\%20\%281\%29.pdf [https://perma.cc/JEG5-GVM5]. For a list of COAPI member institutions, see COAPI Members, SPARC* ${ }^{*}$ http://sparcopen.org/coapi-members/ [https://perma.cc/DP7D5LP7].
}

7 Manuscripts must be made publicly available no later than twelve months after the official date of publication. The policy applies to manuscripts accepted for publication on or after April 7, 2008. See U.S. Dep't of Health \& Human Services, NIH Public Access Policy Details, NIH: PUBLIC ACCESS POLICY, http://publicaccess.nih.gov/policy.htm [https://perma.cc/ZT7X-8TMC].

8 Memorandum from John P. Holdren, Director, Executive Office of the President, Office of Science and Technology Policy for the Heads of Executive Departments and Agencies on Increasing Access to the Results of Federally Funded Scientific Research (Feb. 22, 2013) (on file with the author).

9 The White House memorandum covers agencies under large departments such as the Departments of Labor, Health and Human Services, and Education, as well as scientifically active agencies such as the National Science Foundation and NASA, all of which have begun releasing their draft policies. For a summary of federal agency public access plans, see White House Directive on Public Access to Federally Funded Research and Data, ASS'N OF RES. LIBR., http://www.arl.org/focus-areas/public-access-policies/federallyfunded-research/2696-white-house-directive-on-public-access-to-federally-fundedresearch-and-data [https://perma.cc/JU8F-YQEL]. See also Andrea Peterson, Half of taxpayer funded research will soon be available to the public, WASH. POST (Jan. 17, 2014), http://www.washingtonpost.com/blogs/the-switch/wp/2014/o1/17/half-of-taxpayerfunded-research-will-soon-be-available-to-the-public/ [https://perma.cc/47PA-LGFT]. 
Similar policies are also being proposed and implemented in individual states ${ }^{10}$ and in other countries. ${ }^{11}$ While the policies differ in detail, all are aimed at increasing public access to publicly funded work. In addition, regardless of policy, publishers increasingly agree to contracts with authors that allow authors to post final, but unformatted, articles in institutional repositories. ${ }^{12}$

These policies and practices generally apply to research article manuscripts; public or open access to e-books is at an earlier stage. However, some publishers-particularly academic presses-are beginning to develop open access publishing models for monographs. ${ }^{13}$ The National Endowment for the Humanities has launched an initiative to make unavailable, out of print, or otherwise restricted-use books openly accessible. ${ }^{14}$ In addition, universitysupported initiatives like Knowledge Unlatched have developed funding models whereby libraries share the cost of making books openly accessible. ${ }^{15}$

Academic libraries have emerged as key players in this move to open access as they rapidly develop platforms that provide digital access to scholarship. As libraries and archives increasingly move into

\footnotetext{
${ }^{10}$ See, e.g., California Taxpayer Access to Publicly Funded Research Act, CAL. Gov'T CODE $§$ 13989.6 (Westlaw 2015); New York Taxpayer Access to Publicly Funded Research Act, A180-2013, Assemb. B. A180A (N.Y. 2013-2014); S4050-2013, S. B. S4050 (N.Y. 20132014); Open Access to Research Articles Act, 110 ILL. CoMP. STAT. 61/1 et seq. (2013).

${ }^{11}$ See, e.g., Canadian Tri-Agency Open Access Policy on Publications; RCUK Policy on Open Access; European Commission Horizon 2020 Framework Programme for Research and Innovation. Other countries with open access policies include Peru, Brazil, Argentina, and Mexico. See COAPI Members, supra note 6.
}

${ }^{12}$ See David Hansen, Understanding and Making Use of Academic Authors' Open Access Rights, 1 J. LIBRARIANSHIP \& SCHOLARLY COMM. 1, 2 (2012), http://doi.org/10.7710/21623309.1050 [https://perma.cc/LZT7-UTX2]. For a searchable database of publishers' policies regarding author posting of journal articles in open access repositories, see Publisher copyright policies \& self-archiving, SHERPA/ROMEO, http://www.sherpa.ac.uk/romeo [https://perma.cc/47PA-LGFT].

13 For a list of open access monograph projects and initiatives, see TBI CoMmUNICATIONS, A REVIEW OF OPEN ACCESS BOOK PUBLISHING ON BEHALF OF THE OBERLIN GROUP 8-12 (2013).

14 Humanities Open Book Program, NAT'L ENDOWMENT FOR THE HUMAN., http://www.neh.gov/grants/odh/humanities-open-book-program [https://perma.cc/G6XX-AMKK].

15 KNOWLEDGE UNLATCHED, http://www.knowledgeunlatched.org/ [https://perma.cc/MA3F-HGMG]. 
the online open access space, they are also increasingly thrust into debates over the DMCA $\S 512$ notice and takedown regime. Section 512's safe harbor from copyright liability is aimed at online services that host material contributed by others; historically, libraries did not often host materials posted by others and were therefore unlikely to be eligible for this protection. ${ }^{16}$ Newer institutional open-access repositories, however, may hold many works placed there by third parties, usually authors. These author-directed postings to institutional repositories may put academic libraries into the role of host, thus bringing them under the aegis of the formal notice and takedown system created by the DMCA.

We sought to study this potential shift in libraries' interaction with notice and takedown for two main reasons. First, as noted, academic libraries are continuing their crucial societal role to preserve and provide access to knowledge by acting as important players in the open-access ecosystem; this makes their experience with takedown a potentially important factor in the robustness of this ecosystem. Second, librarians have long had sophisticated, careful, and publicminded approaches to copyright and copyright policy. Their approaches to managing takedown requests are thus likely to be useful in understanding how actors with a public mission balance the competing interests inherent in the practice of notice and takedown and how well these complexities can be managed by such actors. ${ }^{17}$

We explored these topics by fielding a survey instrument asking libraries about their experiences with takedown notices, and by following up in more detailed interviews with a subset of respondents. Through this method, we examined current library interaction with notice and takedown regimes, including the frequency of takedown requests, the type of content targeted, the concerns expressed by those sending takedown requests, and library responses to these requests.

We found that there are relatively few historical examples of library content being targeted with DMCA takedown notices; however,

\footnotetext{
${ }^{16}$ Some campus libraries, however, once served as information technology providers for campuses and may rarely still review and process DMCA notices in this capacity.

${ }_{17}$ While Congress set out the basic balance in section 512, there is room for further balancing in the everyday practice of notice and takedown, which is thus approached differently by different actors. See, e.g., JENNIFER M. URBAN, JOE KARAGANIS \& BRIANNA SCHOFIELD, NOTICE AND TAKEDOWN IN EVERYDAY PRACTICE 1 (2016) (describing the practice of notice and takedown by some types of notice senders and online service providers).
} 
DMCA notice and takedown has recently begun to take on a greater role for academic libraries as library, author, and publisher interests and activities converge. The extent of this shift and its effect are yet to be seen, but libraries' experiences thus far already point to some recommended practices, which we discuss in Section IV.

We also found that, while formal DMCA notices currently appear to be rare, academic libraries regularly encounter a wide variety of other takedown requests. Many of these requests are less formal than DMCA notices. As described further below, these non-DMCA requests include both copyright-based requests targeting material that is digitized, curated, or posted online by the library itself (to which DMCA protections do not apply), and requests initiated for noncopyright reasons like privacy. Libraries' experience with these types of non-DMCA takedown requests is both longstanding and ongoing. Libraries' management of these requests forms a crucial component of their overall approach to takedown. Non-DMCA takedown requests seem likely to continue, and may grow, as libraries continue to build open repositories.

We describe our findings below, in Sections II and III. In Section IV, we discuss the findings and offer some recommendations to help libraries and publishers develop effective methods for managing takedown requests. Section $V$ concludes.

A note on our methods is in order. We draw our findings from survey responses and interviews with academic librarians, supplemented by publicly available information. We recruited survey respondents through a modified "snowball" method. We first distributed the survey to library contacts in the Berkeley Digital Library Copyright Project and Digital Public Library of America networks and through library-focused listservs. These initial contacts then forwarded the survey to other relevant library contacts in their networks. Through this method, we expected to reach a wide range of academic libraries. The survey instrument ${ }^{18}$ covered topics such as:

- whether the library itself evaluates takedown notices or whether the notices are sent to another department;

- when the library received its first takedown notice, if any;

- how many notices are received by year;

\footnotetext{
${ }^{18}$ See infra Appendix A.
} 
- whether the number of notices received has changed over time;

- which of the library's services are most frequently targeted;

- what the typical claims in the notices are;

- what types of review systems are in place for evaluating notices;

- how often notices result in takedown of the targeted material; and

- whether the library takes down material absent a valid claim under $\S 512$.

Where we found it necessary to gather additional information or clarify responses, we followed up with interviews.

Overall, our findings reflect eleven survey responses and five indepth interviews with individuals at academic libraries responsible for addressing takedown requests received for content in digitized collections. This yield is rather small relative to our outreach efforts, and we followed up with potential respondents to find out why. The reasons appear to reflect both organizational characteristics specific to academic libraries and the roles libraries generally have played in the online ecosystem. Primarily, we heard from those who elected not to answer our survey that, on many campuses, designated agents outside the library, often based in information technology departments, receive DMCA takedown notices. This leaves librarians with limited knowledge of the notices. More generally, we heard that potential respondents did not answer the survey because they lacked experience with DMCA takedown notices and thus did not think their responses would be useful. A follow-up study of academic campus DMCA agents would be beneficial, as would a follow-up study in future years after digital repositories have developed further.

\section{DMCA TAKedown ReQuests: CuRRently Rare, But UnSETtLed}

By all publicly available accounts, buttressed by our surveys and interview discussions with librarians, academic libraries have historically received few formal DMCA takedown requests. However, recent efforts by Reed Elsevier ("Elsevier") to clear contested articles from online repositories, and notice-sending efforts by third-party "rights enforcement organizations" ("REOs"), have together raised librarians' concerns about a potential increase in DMCA requests. 
As demand grows to make academic authorship available through institutional repositories, academic libraries have taken the lead in establishing, implementing, and maintaining repositories to make academic works available on the Internet. ${ }^{19}$ Library-directed repositories often host articles authored by their faculty and graduate students, and sometimes host articles by authors from other institutions. In establishing these online-accessible repositories, libraries are increasingly becoming "online service providers" ("OSPs") as defined by the DMCA. Thus, they may increasingly become eligible for the protections offered by DMCA, and subject to the responsibilities it places on OSPs. ${ }^{20}$ Under DMCA notice and takedown procedures, copyright owners can submit a notice to an OSP requesting that allegedly infringing material be removed from the provider's service; this often results in the OSP taking the material down. ${ }^{21}$ Importantly, in return, the DMCA gives OSPs that follow the Act's requirements a safe harbor from secondary liability for copyright infringement by their users. These formal DMCA "takedown" notices and the accompanying safe harbors had much less relevance to libraries before online repositories began growing, because libraries were less often in the position of hosting or linking to material posted by others.

The applicability of the safe harbors is subject to a number of limitations, the effects of which vary depending on the repository design. Critically, the safe harbors do not apply when the service provider itself uploads the material..$^{22}$ At least one recent review finds that, although authors increasingly initiate submissions to institutional repositories, this is almost always through a mediated

\footnotetext{
${ }^{19}$ See Ellen Dubinsky, A Current Snapshot of Institutional Repositories: Growth Rate, Disciplinary Content and Faculty Contributions, 2 J. LIBRARIANSHIP \& SCHOLARLY COMM. 1, 2 (2014), http://doi.org/10.7710/2162-3309.1167 [https://perma.cc/6MML-GKHD].

${ }^{20}$ Note that our survey and interview findings focus on takedown requests received for hosted content under 512(c) and do not explore safe harbors that might apply to library activities under 512(a) or 512(d). For an explanation of the importance to libraries of the safe harbors provided under 512(a) for library provision of internet service and under 512(d) for libraries' role providing information location tools, see Hearing on Section 512 of the Digital Millennium Act Before the Subcomm. on Courts, Intellectual Property and the Internet of the H. Comm. on the Judiciary, 113th Cong. 4-5 (2014) (written statement of the Library Copyright Alliance).
}

${ }^{21} 17$ U.S.C. § 512(c) (2014).

${ }^{22} I d$. 
submission process and after personal and direct contact with institutional repository administrators. ${ }^{23}$ The question is further complicated by the respondeat-superior relationship that could exist between authors local to a university and a repository. ${ }^{24}$ The resulting mixed nature of institutional repositories, which may include authoruploaded content, library-mediated submissions, and even libraryuploaded content, make the application of DMCA safe harbors less clear. As a result, libraries may feel more uncertain about whether DMCA protection applies than under models that rely exclusively on user-directed content. Uncertainty about the availability of the safe harbors arises also when libraries exercise significant curatorial control over the material in the repository. 25

Given the historical mismatch between libraries' goals and practices and the intermediary-focused safe harbors, we expected that libraries would not have received many DMCA notices prior to branching out into repository hosting. Indeed, that is what we found in both publicly available accounts and in our surveys and interview discussions with librarians. Although several digital library collections have DMCA takedown policies available online, ${ }^{26}$ it appears that, until

\footnotetext{
23 For a description of the evolution of faculty-initiated submissions to institutional repositories and the continued involvement of institutional repository administrators in the submission process, see Dubinsky, supra note 19.
}

24 The DMCA does, however, provide relatively clear guidance regarding the imputation of knowledge in this situation. Subject to some exceptions and educational requirements, when a faculty member or graduate student pursuing teaching or research has knowledge or awareness that his or her activities are infringing, that knowledge should not be attributed to the institution. 17 U.S.C. $\S 512(\mathrm{e})$ (2014). The $\S 512(\mathrm{e})$ safe harbor thus provides some additional protection to universities for faculty and graduate students who themselves post, or otherwise use, materials. Historically, it has protected academic institutions from knowledge imputation where faculty and researchers post materials on personal, departmental, or lab sites. In theory, § 512(e) could provide some additional protection, beyond $\S 512(\mathrm{c})$, in cases where faculty and graduate students post materials into a library repository.

25 The safe harbors are not applicable where the service provider has the right and ability to control the infringing activity and receives a financial benefit directly attributable to such activity. 17 U.S.C. $\$ 512(c)(1)$ (B) (2014). One of our respondents noted that because of the degree of curatorial control it has over its service, counsel advised the library that at least one of its repositories is not eligible for DMCA safe harbor protection.

${ }^{26}$ See, e.g., California Digital Library Terms of Use, U.C.: CAL. DigiTAL LiBR., http://www.cdlib.org/about/terms.html [https://perma.cc/A8BC-CAA8]; Take-Down Policy, HATHI-TRUST DigiTAL LiBR., http://www.hathitrust.org/take_down_policy [https://perma.cc/NX5H-8CSG]; About the Collections: Takedown Policy, FORSYTH LIBR. DigiTAL COLLECTIONS, http://contentcat.fhsu.edu/ [https://perma.cc/M4BA-SDH6]. 
recently, publishers rarely used DMCA notices to target digitized works in academic library collections.

In late 2013, however, Elsevier, publisher of nearly 2,000 research journals, ramped up its DMCA notice-sending activities to enforce the rights it holds in academic articles. As part of this effort, Elsevier sent over 2,800 DMCA takedown notices over several weeks to academia.edu, a social networking site where academics share research papers. ${ }^{27}$ Concurrent with this effort, Elsevier also began sending takedown notices to individual researchers and universities targeting articles posted on university-hosted pages. Harvard University, the University of California-Irvine, and the University of Calgary were among the recipients of these notices, which targeted department, lab, course websites, and the personal webpages of faculty. ${ }^{28}$ In a public statement about the notices, Elsevier had said that it "issue[s] takedown notices from time to time when the final version of published journal articles is posted on unauthorized public websites." 29

Elsevier's activities sent a ripple of concern through the academic library community. Respondents noted that if such efforts were to grow, open access repositories for academic work could be threatened..$^{\circ}$

${ }_{27}$ Olivia Solon, Elsevier clamps down on academics posting their own papers online, WIRED (Dec. 17, 2013), http://www.wired.co.uk/news/archive/2013-12/17/elsevierversus-open-access [https://perma.cc/8HQ8-NY7Q].

${ }^{28}$ Andrea Peterson, How one publisher is stopping academics from sharing their research, WASH. POST (Dec. 19, 2013), http://www.washingtonpost.com/blogs/theswitch/wp/2013/12/19/how-one-publisher-is-stopping-academics-from-sharing-theirresearch/ [https://perma.cc/FR7M-5XAY].

29 Tom Reller, A comment on takedown notices (with update), ELSEVIER CONNECT (Dec. 6, 2013), http://www.elsevier.com/connect/a-comment-on-takedown-notices [https://perma.cc/5QKF-SEVK].

$3^{30}$ In the time since we communicated with our respondents, these issues have intensified. In May 2016, Elsevier acquired SSRN, a popular repository for social science research. Following the acquisition, SSRN reportedly began removing papers from the repository without notice. See Howard Wasserman, SSRN Postings and Copyright, PRAWFSBLAWG (July 15, 2016), http://prawfsblawg.blogs.com/prawfsblawg/2016/07/ssrn-postings-andcopyright.html [https://perma.cc/X666-VZNX]. SSRN later described these removals as mistakes, not a change in policy. Tiffany Li, SSRN and Open Access for Non-Institutional Scholars, Citizen TECHNOLOGIST (Aug. 4, 2016), https://ctsp.berkeley.edu/ssrn-and-openaccess-for-non-institutional-scholars [https://perma.cc/PN5J-5RD6]. Nevertheless, these events have led some to call on authors to consider alternative repositories for their works. See Is it Time for Authors to Leave SSRN, AUTHORS ALL. BLOG (July 17, 2016), 
Elsevier's reference to the "final version" of journal articles highlights a common practice among publishers. Many authors are asked to transfer some or all their copyright rights in an article to their publisher when signing a publication agreement, and relatively few publishers allow authors to post the final published version of their articles online. More often, however, authors are permitted by the terms of their agreements to self-archive their own final version of their articles-after peer review, but before the publisher formats it in the journal layout. Elsevier's statement distinguished these versions of the articles, as is common in academia.

Notwithstanding Elsevier's attempt to distinguish its policing as aimed only at final, formatted versions, its increased enforcement prompted both criticism and concern among library respondents. In interviews, critics of Elsevier's notice sending stated that authors' practice of posting copies of their articles online is widespread, promotes access to research, and allows subsequent researchers to build on existing work. And-though online posting of final, formatted articles by authors may be formally contrary to publishing agreements-respondents said that posting is a practice historically tolerated by publishers as a modern-day equivalent of authors circulating the free physical off-print copies they were given.

Elsevier's action thus inspired strong concern that these norms of tolerance could be under attack. Respondents feared that the Elsevier takedown notices could signal a change in practice, with publishers beginning to use takedown notices to enforce the formal rights signed over to them by article authors. Library respondents expressed concern that, if this enforcement becomes the new norm, they will not have the capacity to process these requests at scale. Substantively, library respondents worried that an increase in these requests could result in valuable scholarship being removed from online repositories, thus limiting libraries' ability to fulfill their missions to preserve and disseminate knowledge. One respondent noted that, particularly in the case of older articles, an author may no longer have copies of prepublication versions of the article. If the final, formatted version is taken down because it violates the terms of the author's agreement, the author may be left without the ability to self-archive because she would no longer have a version available to deposit online that is in

http://www.authorsalliance.org/2016/07/17/is-it-time-for-authors-to-leave-ssrn/ [https://perma.cc/RZ5A-TUXK]. 
compliance with her agreement. This could severely limit the benefits of open repositories in addition to harming individual authors.

Respondents told us that their concerns were amplified when, several months after Elsevier sent its notices, the California Digital Library at the University of California reported receiving its first DMCA takedown notice, from a third-party REO working for the American Society of Civil Engineers. ${ }^{31}$ The notice targeted nine academic articles uploaded by authors to eScholarship, the University of California's open access repository. ${ }^{32}$ This notice resulted in the removal of all nine articles.

One survey respondent, an international academic library, also reported receiving DMCA takedown notices for articles posted by authors to its institutional repository. Notably, as with the notice sent for material in the eScholarship repository, the notice was sent by a third-party REO working on behalf of the publisher-not the publisher itself-mirroring a larger trend in the rise of rights enforcement organizations in takedown notice sending. 33 This respondent reported-as with the Elsevier notices and the notice received for articles in the University of California's eScholarship repository-that the articles posted to the repository appeared to be the publisherformatted version of the article rather than the author's final version. The library responded to the request by removing the articles from the repository because of this versioning issue.

One library respondent who has received a single takedown notice targeting several articles in its institutional repository explained how time consuming it can be to address a takedown request. In the wake of the Elsevier notices, the respondent's institution put noticehandling procedures in place to prepare for the potential future receipt of a takedown notices. Just a few months later, the institutional repository received its first DMCA takedown notice and implemented the new procedures. The plan included alerting relevant university administrators; notifying librarians at the targeted authors' institutions and ensuring they were ready to respond to the authors'

\footnotetext{
${ }^{31}$ Katie Fortney, ASCE Takedown Notices, U.C.: OFF. OF SCHOLARLY CoMm. (Mar. 13, 2014), http://osc.universityofcalifornia.edu/2014/o3/asce-takedown-notices/ [https://perma.cc/9Y6R-JT9N].

${ }^{32} I d$.

33 Daniel Seng, The State of the Discordant Union: An Empirical Analysis of DMCA Takedown Notices, 18 VA J.L. \& TECH 369, 19-20 (2014).
} 
questions; and preparing materials for the targeted authors that described their options. Staff at the repository also personally engaged in dialogue with the affected authors. In total, this respondent reported that about twenty to thirty hours of staff time were spent addressing the notice.

Not all of the notices libraries reported were issued because the version of the article posted online was in the publisher-formatted version rather than the author's final version. One survey respondent reported receiving a DMCA takedown notice in 2013 from an REO acting on behalf of Elsevier, targeting a single article in the university's repository. 34 The article at issue was a 2009 article that is subject to the National Institutes of Health ("NIH") Public Access Policy. (As described above, NIH's Public Access Policy requires researchers to submit final peer-reviewed journal manuscripts that arise from NIH funds to the digital archive at PubMed Central.) 35

Upon receipt of the notice, the campus security officer removed the article from the online repository and notified the institutional repository librarian of the removal. Library staff then verified that the article was posted to the repository after the designated NIH embargo period had run, and that the version posted was the author's version. Indeed, staff meticulously reviewed the version posted online and the publisher's final version, comparing the two versions word-by-word to verify that the correct version of the article was archived. Staff then notified the REO that the article was posted in full compliance with the NIH Public Access Policy and Elsevier's own policy, which allows authors "to post their accepted author manuscripts on their personal or institutional web site." 36 Within four hours of notification, the REO rescinded the takedown notice and the article was later reinstated to the repository. Later, the repository received an email from the client relations manager of the REO, acknowledging that there was an "obvious error/breakdown in [its] validation process" and stating that the repository's domain would be whitelisted.

\footnotetext{
34 Although this was a formal DMCA notice, it is unlikely that the DMCA safe harbors would have applied as the library itself was responsible for uploading the article to its repository.

35 U.S. Dep’t of Health \& Human Services, supra note 7.

${ }^{36}$ Elsevier NIH Policy Statement, ELSEVIER, https://www.elsevier.com/about/openscience/open-access/agreements/elsevier-nih-policy-statement [https://perma.cc/4CBH$74 \mathrm{DE}]$.
} 
Although these examples apparently remain rare, our library respondents expressed concern that a shift by publishers to regularly using takedown notices and REOs may begin to undermine or limit efforts to make academic works accessible. Librarians especially worried that their limited resources and time-constrained abilities to investigate the claims in DMCA notices would result in overzealous takedown if these notices are sent in large numbers. Respondents reported that this is of special concern when REOs send notices using unrefined algorithms that may misidentify content as infringing.

DMCA notices to libraries are a relatively new and infrequent occurrence for libraries. Most of our respondents relayed discomfort with managing the process, and especially with managing potential institutional exposure to copyright liability. In part, this discomfort stemmed from a lack of institutional information sharing and consensus. Several respondents expressed uncertainty about whether their notice-handling approach is consistent with the handling practices at other institutions, stating that DMCA takedown requests to libraries are too infrequent for cross-institutional norms to have developed for handling in the academic library community. ${ }^{37}$ Despite this lack of confidence, respondents who have processed one or more DMCA takedown request described undertaking sophisticated analysis and decision-making in their handling of the notices.

For the moment, academic librarians reported a variety of institutional responses to increased notice sending activity. These included educating authors about what rights authors typically retain and what rights they typically sign away in publication agreements, and by offering assistance to authors in finding ways to share their work while complying with the terms of their publications agreements. ${ }^{38}$ Some libraries also encouraged authors to negotiate

\footnotetext{
37 This is in contrast to librarians' description of handling non-DMCA notices, around which a variety of norms and practices has developed. See infra Section III.

${ }^{38}$ See, e.g., Meredith Kahn, Academia.edu and Elsevier: Assistance for U-M Authors, Mich. PUB.: U. OF MiCH. LIBR. (Dec. 9, 2013), http://www.publishing.umich.edu/2013/12/o9/academia-edu-and-elsevier-assistancefor-u-m-authors/ [https://perma.cc/4GSP-RTRU]; Katie Fortney, Elsevier Takedown Notices for Faculty Articles on UC Sites, U.C.: OFF. OF SCHOLARLY COMM. (Dec. 20, 2013), http://osc.universityofcalifornia.edu/2013/12/elsevier-takedown-notices/ [https://perma.cc/3FT9-S75J]; Marilyn Billings, Laura Quilter \& Charlotte Roh, Elsevier Takedown Advisory, UMASS AMHERST LIBR. (Jan. 2014), http://www.library.umass.edu/services/scholarly-communication/news-and-events-inscholarly-communication/elsevier-takedown-advisory-january-2014/ [https://perma.cc/N4SS-LYSU].
} 
more favorable terms that allow authors to use and display their own articles in any future publication agreements, or to consider publishing in the future with an alternative publisher that would allow such a practice. 39

Librarians also reported urging authors to consider how institutional open access policies can be used to preserve and provide access to an author's future scholarly work. $4^{\circ}$ Librarians pointed out that the recent takedown requests underscore the importance of institutional open access policies that empower authors to archive and make articles freely accessible. Such policies may require that faculty grant their university a non-exclusive license before assigning any further rights to publishers-or reserve sufficient rights-to make their articles freely available to the public in an open access repository. ${ }^{41}$ When an article is licensed to a publisher in compliance with the open-access policy, or where rights are assigned to a publisher exclusive of the prior grant to the institution, it can then be deposited in an institutional repository without infringing the publisher's copyrights..$^{42}$ As an example, the University of California's Open Access Policy FAQ webpage states:

\footnotetext{
39 Id.; Fortney, supra note 31.

40 See, e.g., Elsevier Takedown Notices: A Q\&A with Peter Suber, HARV. LIBR. (Apr. 17, 2014), http://library.harvard.edu/o3142014-1552/elsevier-takedown-notices-qa-petersuber [https://perma.cc/77SN-BRNA].
}

${ }^{41}$ See, e.g., Open Access Policy for the Academic Senate of the University of California, U.C.: OFF. OF SCHOLARLY COMM., http://osc.universityofcalifornia.edu/open-accesspolicy/policy-text/ (adopted July 24, 2013) [https://perma.cc/E3TT-ZAU5]; Open Access Policies, HARV. U. LIBR.: OFF. FOR SCHOLARLY COMM., https://osc.hul.harvard.edu/policies [https://perma.cc/9XSA-FQUG]. Variations of these models exist. For example, the University of Michigan's copyright policy provides that the University reserves the nonexclusive right to preserve, archive, and host faculty's scholarly works in its institutional repositories. See Copyright Basics - University of Michigan Copyright Policy, U. MICH. LIBR., http://www.lib.umich.edu/copyright/university-michigan-copyright-policies [https://perma.cc/FA8T-M28J].

$4^{2}$ A nonexclusive license prevails over a conflicting subsequent transfer of copyright ownership if the license is memorialized in a signed writing. 17 U.S.C. § 205(e) (2014). Institutional repositories that require submitting authors to grant an express, written nonexclusive license to reproduce and distribute the article expect to rely on those licenses if the author subsequently transfers the rest of the copyright to a publisher. Many institutions rely on permission mandates to effectuate the grant of nonexclusive license. For a comprehensive analysis of how $\S 205(\mathrm{e})$ applies to open access policies, see Eric Priest, Copyright and the Harvard Open Access Mandate, 10 NW. J. TECH. \& INTELL. PROP. 377, 395 (2012). See also SimON J. FrankEL \& SHANNON M. NESTOR, OPENING THE DOOR: HOW FACULTY AUTHORS CAN IMPLEMENT AN OPEN ACCESS POLICY AT THEIR INSTITUTION 9- 
Publishers' policies will not, by default, represent the terms of institutional open access policies. You should read, and keep, any agreement you sign, but understand that the UC OA Policy is intended to preempt or augment these publisher default terms. This is true whether the publisher requires a copyright transfer or not. If your publisher isn't requiring you to opt out by getting a waiver, you are fully within your rights to take advantage of UC's policy. 43

However, institutional open access policies do have limitations. Prominently, they generally are not retroactive. Because the policies are relatively new, publication agreements that predate an author's institution's open access policy usually are not covered. Accordingly, posting past articles to an institutional repository may not be allowed under the terms of the author's older agreements. In addition, in line with the existing norms of tolerance, open access policies sometimes only apply to the author's final version, not the publisher-formatted version.

Despite their concerns that increased DMCA notice-sending activity could harm open access repositories and their preservation and access missions more generally, library respondents also readily acknowledged the importance of the safe harbors to their institutions' abilities to provide repositories and related services.

Finally, while it is too early to tell whether the recent spate of DMCA notices to academic libraries and repositories is the start of a new trend, many librarian respondents expressed hope that the experience may provide an impetus for authors to carefully consider what rights they transfer in publication agreements going forward, and that it might increase interest in academic open access policies.

\section{NON-DMCA TAKEDOWN REQUESTS}

While formal DMCA takedown requests are still relatively rare, librarians regularly field other types of requests to remove material from online collections. These "non-DMCA" requests often target

10.

43 Policy FAQ, U.C.: OfF. OF SCHOlarly Comm. (2014), http://osc.universityofcalifornia.edu/open-access-policy/policy-faq/ [https://perma.cc/N2SB-GL2Q]. 
material that libraries directly curate, digitize, and post, and the majority cite reasons other than copyright as motivation for the request; accordingly, the DMCA generally does not apply. Respondents indicated that non-DMCA requests predominate over formal DMCA takedown requests. Notably, they also expressed greater confidence in handling non-DMCA requests, particularly those that do not touch on copyright issues, which they deal with using longstanding informal practices.

Non-DMCA requests arise in a variety of situations, such as when private or sensitive information is made available online; when an author is embarrassed by a digitized work; or, less often, when copyright or other creative interests are implicated. In such cases, libraries often address senders' complaints by implementing informal procedures tailored to the circumstances of each takedown request.

Nonetheless, many libraries reported that they have instituted takedown policies that look similar to DMCA notice and takedown for those repositories or requests that are not technically eligible for DMCA safe harbors. Typically, a library will provide the means for a rightsholder or other concerned party to contact the library to request the removal of materials in the digitized collection. Several library respondents noted that they follow the practices laid out in the Online Computer Library Center ("OCLC")'s "Well-intentioned practice for putting digitized collections of unpublished materials online," ("WellIntentioned Practice"), including adopting a takedown policy.44 Similarly, recent best practices guidance for handling orphan works suggests that, although institutions should not simply promise to remove material in response to complaints, they should offer a way to submit questions, comments, concerns, or other additional information about works in the collection. 45

\footnotetext{
44 ONLINE COMPUTER LIBRARY RESOURCE CENTER, WELL-INTENTIONED PRACTICE FOR PUTTING DIGITIZED COLLECTIONS OF UNPUBLISHED MATERIALS ONLINE (2010), http://www.oclc.org/content/dam/research/activities/rights/practice.pdf [https://perma.cc/VU6N-8V4D].
}

45 Statement of Best Practices in Fair Use of Collections Containing Orphan Works for Libraries, Archives, and Other Memory Institutions, CTR. FOR MEDIA \& SOCIAL IMPACT (Dec. 2014), http://www.cmsimpact.org/fair-use/best-practices/statement-best-practicesfair-use-orphan-works-libraries-archives\#statement [https://perma.cc/DTC7-NYJ6]. Disclosure: Author Jennifer Urban co-facilitated the production of this Statement of Best Practices, which is based on workshops and intensive deliberative group meetings with librarians and archivists. 
These practices reflect a general understanding among librarians that, even when the library may not be technically eligible for safe harbor from liability, creating a path through which concerned parties can contact the library and engage in discussion may nonetheless address concerns and prevent further escalation. ${ }^{46}$

Notably, library respondents reported that many non-DMCA requests do not lead to removal of the material. Rather, by providing a way for concerns to be aired, the informal process can allow discussion and agreement that addresses concerns and prevents further dispute. For example, several respondents reported that many complainants are satisfied if sensitive portions of the material are redacted.

Non-DMCA takedown requests separate into two broad types: requests for removal for reasons other than copyright, such as privacy or defamation; and less often, requests for removal for copyright or related reasons.

\section{A. Requests based in claims other than copyright}

Both survey and interview respondents noted that senders of nonDMCA takedown requests most frequently cite reasons other than copyright when requesting removal. In particular, libraries field many requests to take down material that the sender views as private or otherwise sensitive. Respondents reported viewing the receipt of a non-copyright takedown request as the start of a dialogue between the library and the complainant. They reported that the end goal of this dialogue is to strike a reasonable balance between addressing appropriate concerns while maintaining the institutional goals of preserving and providing access to information.

Responses to complaints about sensitive or private information in a posted work are an example. Respondents reported that librarians and archivists make every attempt to review materials and redact private information (such as addresses or Social Security numbers) before posting digitized material online, but that occasionally they miss something. Some libraries reported that they often remove material in cases where the notice includes "identification of sensitive

\footnotetext{
46 This was a common theme among our respondents. It was also a common theme voiced by librarians in a series of deliberative discussions in a 2012-2013 study Urban conducted with Patricia Aufderheide, David Hansen, Meredith Jacob, and Peter Jaszi, see infra note 49. The study served as the foundation for the Statement of Best Practices project.
} 
materials previously unnoticed [by the library]." Others will reach an agreement with the notice sender that stops short of completely removing the item from the collection. As examples, respondents described restricting access to sensitive material to website visitors with institutional credentials or redacting the part of the material or collection identified as sensitive.

Dissertations are now commonly published in a library's online collection; these are frequent targets of non-copyright requests for takedown. Our respondents reported that these requests almost always come from dissertation authors themselves, despite the fact that authors often grant the institution an explicit license to publish 47 and are often given an upfront option to request an embargo period before the dissertation goes online. ${ }^{48}$ Embargo options appear to be rarely exercised at the time the dissertation is completed. One respondent indicated that fewer than ten percent of dissertation authors request an embargo period prior to publication. Yet authors' views may change as time goes on. Respondents described a wide variety of reasons cited by dissertation authors requesting takedown, including embarrassment about the quality of early writings; concerns that online availability of the work might prevent later publication; and concerns for sources. In a few cases, authors have expressed concern about the safety and anonymity of family members or friends in foreign countries who may be punished for the author's political views.

Libraries reported that they manage requests to remove dissertations from online repositories in a variety of ways; they do not always remove the targeted material. They may instead, for example, address publisher concerns by delaying including the work in the repository for a specified embargo period after publication (where the would-be publisher is satisfied by an embargo period), or restricting access to the work to affiliates of the institution (in cases involving concerns of safety, privacy, or other issues related to sensitive dissertation content). One respondent stated that ninety percent of

\footnotetext{
47 We note that dissertation licenses may be required for degree completion, limiting dissertation authors' ability to choose whether or not to grant a license. Though we did not discuss it with respondents, this potentially could affect some dissertation authors' reaction to having their work posted in online repositories.

48 The embargo option is not universal. Although this was not mentioned by our respondents, one common reason for delaying publication of a dissertation is to avoid disclosing patentable inventions before a patent can be granted.
} 
the time, a two-year embargo satisfies the dissertation author and her publisher.

Our findings regarding these non-DMCA notices are in line with what librarians have reported about takedown requests in other venues. For example, others have noted that copyright concerns are not especially prominent. A recent report on the challenges libraries face when digitizing orphan works found that complaints to libraries about digitized collections typically concerned privacy-not copyright-and often stemmed from some potentially embarrassing fact revealed by a digitally accessible work. 49 Also consistent with our respondents' reports, the orphan works study respondents reported that in all situations where the complaints were legitimate, the complaining party and the collection owner "came to a mutually acceptable solution, such as redaction or removal of the work into a dark archive."5o

\section{B. Copyright-based requests that fall outside the DMCA's notice and takedown procedures}

Though other types of requests are more common, libraries also receive takedown requests grounded in copyright concerns that nonetheless fall outside the DMCA, either because the library is directly curating or posting the material, or because the notice does not meet the DMCA's requirements. Like DMCA notices, these notices present the issue of potentially costly copyright liability. Library respondents who had received these non-DMCA copyright requests reported using great care in analyzing the merit of the underlying copyright claim. They described undertaking careful analyses, focused on balancing adherence to copyright law and minimizing liability risk to their institutions with fulfilling their missions to provide access to information. Respondents reported that it is typical to spend several

\footnotetext{
49 Jennifer Urban, David Hansen, Patricia Aufderheide, Peter Jaszi \& Meredith JACOB, REPORT ON ORPHAN WORK CHALLENGES: FOR LIBRARIES, ARCHIVES, AND OTHER MEMORY INSTITUTIONS 11 (2013),

http://archive.cmsimpact.org/sites/default/files/documents/report_on_orphan_works_c hallenges.pdf [https://perma.cc/447K-T4GJ]. These concerns most frequently arise for libraries that work with special or other limited collections that contain unpublished and potentially sensitive material, such as letters, photographs, diaries, meeting minutes, and the like. Id. at 12.
}

${ }^{50} I d$. at 11. "Dark" archiving preserves and archives the work, but limits or prohibits access to it. 
hours analyzing the underlying claims in these requests. Sometimes, the sender alerts the library to a relatively straightforward violation, in which case the library will respond by removing the material. In other cases, after assessing the sender's claim, the library will deny the sender's request.

One library respondent provided an example of such a denial. The respondent was contacted by the copyright owner of content used by another author in a dissertation that had been digitized and placed online by the library. The permission obtained by the dissertation author to use the third-party content apparently did not cover online publication. After assessing the claim, the respondent explained to the copyright owner that it believed the use was within the bounds of fair use, and permission was not required. The copyright owner in this case did not pursue the claim.

As a rule, libraries and archives lack the resources to apply this level of attention to every work in a collection. Respondents thus also reported that notices may serendipitously prompt research that leads to discovery of previously unknown information about the materials. Respondents considered this a potential side benefit of the research required to assess a sender's claim. For example, one library that hosts a digital photo archive reported that a copyright takedown request led its staff to carefully analyze microfiche copies of the newspapers where the photographs were originally featured. Through this search, the staff identified the original photographer-thus adding useful information about the photographs to the archive-and determined that the sender of the takedown request had no copyright claim to the material.

\section{DisCUSSION AND RECOMMENDATIONS}

Overall, we found that, although there has been a recent uptick in formal DMCA takedown notices sent to institutional repositories, nonDMCA takedown requests handled through informal systems set up by libraries still predominate. Librarians expressed greater comfort in handling the wide range of notices that arrive through less-formal notice channels than in handling formalized DMCA takedown notices, and concern about potential increases in DMCA notifications.

Indeed, it was striking that librarians expressed such higher levels of confidence handling non-copyright notices, despite the range of issues these notices can raise and despite the fact that balancing some of the issues that commonly provoke them-for example, weighing information-access interests against privacy interests-is widely 
considered to be devilishly difficult. Why might this be? Our findings suggest an answer with two facets. ${ }^{1}$ First, archivists and specialcollections librarians have a long history of handling complaints arising from privacy, embarrassment, security, and other concerns. Second, copyright law allows plaintiffs to demand statutory damages that can, at least theoretically, create extreme liability for an institution; 52 this makes decisions about whether to take down material more fraught.

The difference in experience is key. Time and experience have allowed intra- and inter-institutional norms and practices to develop. Indeed, librarian and archivist experience with these notices dates back to complaints targeted at pre-digital collections. 53 Over years, experiences have been shared within and across institutions in a variety of ways, helping librarians and archivists balance the interests implicated. Respondents reported that their confidence in managing non-DMCA requests expanded through: 1) cross-institution dialogue and the ensuing development of shared informal ideas about "best practices;" 2) guidance from formal best practices documents such as the Well-Intentioned Practice; and 3) a long history of encountering issues that require balancing competing concerns, such as privacy and access. Over this time, libraries and archivists have arrived at a number of solutions that can both accommodate concerns and prevent takedown; indeed, the issues raised are often addressed with solutions that fall short of complete removal of targeted content.

In contrast, many librarians with whom we spoke described operating in the dark with respect to DMCA takedown notices. Librarians reported little knowledge of any norms-based or standardized DMCA takedown practices among similar institutions, especially for particularly challenging requests. Although these librarians often have a solid grounding in copyright law and

\footnotetext{
${ }^{11}$ These themes also consistently arose during the orphan works study Urban undertook with co-researchers. URBAN, HANSEN, AUFDERHEIDE, JASZI \& JACOB, supra note 49.

$5^{2}$ See Pamela Samuelson \& Tara Wheatland, Statutory Damages in Copyright Law: A Remedy in Need of Reform, 51 WM. \& MARY L. REV. 439 (2009). For academic libraries, this concern may be more theoretical than actual, as they are likely to be eligible for limits on statutory damages if they have a reasonable fair use defense. 17 U.S.C. $§ 504(c)(2)(i)$ (2014).
}

53 This was a common theme from participants in the orphan works study Urban undertook with co-researchers. URBAN, HANSEN, AUFDERHEIDE, JASZI \& JACOB, supra note 49. 
experience processing non-DMCA requests, they reported that the potential loss of the safe harbor and the legal liability that might follow a wrong decision make them especially wary when managing DMCA notices. Many respondents described the difficult position of carefully considering and weighing their core mission against the risk of liability for their institutions. Librarians are deeply aware that responding too conservatively to takedown notices by erring on the side of takedown could damage their preservation and access mandates, but are also deeply aware of the potential institutional cost of copyright liability.

Several librarians described how, to avoid overbroad takedown while still conservatively managing liability concerns, they may engage in fact-intensive and time-consuming investigations in response to a single takedown request. For example, as described above, one takedown notice prompted a librarian to undertake a word-by-word examination of an article to ensure that the right version of the article was posted online. It is clear that this level of review is not sustainable at scale.

Investigation into takedown requests by librarians can be further complicated because they lack information about the terms of the publication agreement governing the work. Authors may sign over rights in publication contracts without understanding the complex terms governing the agreement, and, in many cases, libraries do not have sufficient knowledge of or access to the terms of the author's agreement to intelligently respond to takedown requests. While there is a searchable database of journal publishers' standard policies regarding author posting of journal articles in open access repositories, 54 the database does not include older versions of agreements, nor does it include particularized terms that may have been negotiated between author and publisher in any specific agreement. There is no such comparable index for book publishers' policies at all. Relatedly, information about third-party rights in works embedded within the work in question-for example, photographs or other illustrations-may be impossible to find. In the absence of information transparency about the terms to which an author has agreed, respondents explained that libraries may be inclined to act conservatively and take down content even where a publication agreement or third-party work license would have permitted posting.

\footnotetext{
${ }^{54}$ SHERPA/RoMEO, http://www.sherpa.ac.uk/romeo [https://perma.cc/UG79-MJ6R].
} 
Yet in some cases, librarians may not need to look to the terms of individual agreements to confidently reject takedown requests; instead, the use at issue may fall within the bounds of fair use. In evaluating potential fair use of materials in their online collections, librarians can draw on their experience evaluating fair use in copyright-based non-DMCA requests and look to best practices documents for guidance. Best practices documents are limited in scope, not legally binding, 55 and may cover only limited situations. At the same time, they are tailored to the needs of libraries and archives and provide consensus-based guidance on how similarly situated institutions view the application of fair use to the management of content. ${ }^{6}$ Recent case law suggests that fair use can support some library mass digitization activities, recognizing these activities as transformative, and valuable to the public interest. 57

How open access repositories and other library-hosted materials ultimately will fare under the DMCA takedown procedures-and in the face of less-formal demands-remains to be seen. To help libraries effectively manage increased takedown requests while maintaining publishers' ability to police content made available in online repositories, we recommend the following:

\section{- Academic libraries should continue to educate authors about author-friendly publishing practices, and authors should retain more}

\footnotetext{
55 Cambridge Univ. Press v. Patton, 769 F.3d 1232, 1274 (11th Cir. 2014) (discussing how the Classroom Guidelines were not intended to limit fair use).

\begin{abstract}
${ }^{6}$ ASS'N OF REs. LibR., CODE OF BEST PRACTICES IN FAIR USE FOR ACADEMIC AND RESEARCH LIBRARIES (2012), http://www.arl.org/storage/documents/publications/code-of-bestpractices-fair-use.pdf [https://perma.cc/ZQC3-HKB8]; Statement of Best Practices in Fair Use of Collections Containing Orphan Works for Libraries, Archives, and Other Memory Institutions, CTR. OF MEDIA \& SOCIAL IMPACT (Dec. 2014), http://www.cmsimpact.org/fairuse/best-practices/statement-best-practices-fair-use-orphan-works-librariesarchives\# statement [https://perma.cc/N4C9-G756]. But cf., U.S. COPYRIGHT OFF., ORPHAN WORKS AND MASS DIGITIZATION: A REPORT OF THE REGISTER OF COPYRIGHTS 44-46 (2015), http://copyright.gov/orphan/reports/orphan-works2015.pdf [https://perma.cc/3YQWZDQR] (describing some limitations of best practices guidance).
\end{abstract}

57 Authors Guild, Inc. v. Google Inc., 804 F.3d 202 (2d Cir. 2015) (holding that Google's digital reproduction of copyrighted books to create a full-text index of the scanned books and to display of snippets of text from the books in response to a search was fair use); Authors Guild, Inc. v. HathiTrust, 755 F.3d 87 (2d Cir. 2014) (holding that digitizing books to create materials accessible for print-disabled patrons and to create a full-text index was fair use). 
control of their own works. Academic libraries have historically served a role in educating authors about their rights and favorable publishing practices, and should continue to do so. Authors should understand what rights they have in their works, and, where possible, should select publishers with-or negotiate for-contract terms that ensure sufficient authorial control for authors to include their works in open access repositories. ${ }^{8}$ As authors increasingly gain more control over the dissemination and licensing of their works, the strains on libraries to manage rights will decrease.

- Publishers, authors, and academic libraries should take steps to make the terms of publication agreements transparent. Librarians can help authors understand their rights and obligations under their publishing contracts and respond appropriately to takedown requests only when they have visibility into the underlying agreement. Increasing the transparency of contractual practices would help streamline libraries' ability to do so. For example, publishers and academic libraries should agree on uniform metadata to communicate author and institutional rights with respect to works. The metadata should be machine-readable, so that ownership information is automatically available with copyrighted digital works.59 These metadata could include information such as which version of the work, if any, is available for deposit in an open repository and under

\footnotetext{
$5^{8}$ For a resource for authors describing open access publishing options, see LEXI RUBOW, RACHAEL SHEN \& BRIANNA SCHOFIELD, AUTHORS ALL., UNDERSTANDING OPEN ACCESS: WHEN, Why, \& HOW TO MAKE YOUR WORK OPENLY ACCESSIBLE (2015), $\mathrm{http}$ ///authorsalliance.org/wpcontent/uploads/Documents/Guides/Authors\%20Alliance\%20\%20Understanding\%20Open\%20Access.pdf [https://perma.cc/53WU-85FH].

59 For an example of a proposed standardized approach to rights statements and a related technical infrastructure, see Paul Keller \& Emily Gore, The principles for establishing international \& interoperable rights statements, DigITAL PUB. LIBR. OF AM. BLOG (May 11, 2015), http://dp.la/info/2015/o5/11/the-principles-for-establishing-internationalinteroperable-rights-statements/ [https://perma.cc/3HN5-3B6T].
} 
what terms. Such information would help librarians process takedown requests in accordance with publication agreements.

- Academic libraries should continue to support-and authors should embrace-open access policies. Authors subject to institutional open access policies have increased bargaining power vis-àvis publishers, making it easier for them to make their works openly accessible. ${ }^{60}$ As the number of open access policies grows, more works will be unencumbered by contractual terms that prohibit deposit in open access repositories. Authors from institutions without open access policies may also benefit as an increasing number of open access policies prompts a shift in publishing norms. In conjunction with careful notice-sending practices (see below), this will help limit the number of takedown notices that publishers need to send, and that libraries must receive and process.

- Academic libraries should consider developing shared norms and best practices for DMCA notice handling similar to those they have developed for non-DMCA requests. Libraries should develop a shared understanding of how best to handle notices by documenting and exchanging information about their experiences with DMCA takedown notices. Libraries should further improve their approaches by developing and circulating best practices for notice handling based on this shared understanding and informed by relevant fair use case law ${ }^{61}$ and fair use best practices documents. ${ }^{62}$ Creating

\footnotetext{
${ }_{60}$ These policies may, for example, require a prior license to the institution that allows for open access. For more on this point, see 17 U.S.C. § 205(e) (2014). See sources cited supra note 41.

${ }^{61}$ See, e.g., Google Inc., 804 F.3d 202; HathiTrust, 755 F.3d 87; Patton, 769 F.3d 1232.

${ }^{62}$ Ass'N OF RES. LIBR., supra note 56; Statement of Best Practices in Fair Use of Collections Containing Orphan Works for Libraries, Archives, and Other Memory Institutions, supra note 45 .
} 
and following a best practices document for handling DMCA notices could provide libraries with some reassurance that their practices are reasonable and aligned with that of their peer institutions.

- Academic institutions should ensure that librarians have adequate institutional knowledge of DMCA notices directed to library materials, and that library-developed best practices are followed in handling DMCA notices. We found it striking that so many of our potential respondents described difficulty filling out the survey because DMCA notices targeting library materials were received in other departments and were not always forwarded on to libraries, severely limiting librarians' knowledge of the notices. While central administration of DMCA notices may well be institutionally efficient, librarians should be given sufficient information about notices that target library materials-how many notices are coming in, from whom they are coming, and to what resources they are directed-to make handling recommendations. In some cases, the library may be in the best position to process incoming notices. If library-developed best practices arise, they should be followed if possible, regardless of which institutional actor processes a notice. ${ }^{63}$

- Publishers should develop and publicly communicate reasonable notice-sending policies. Publishers should develop transparent notice-sending policies, particularly with regard to open access repositories and self-archived works more generally, to help authors understand what works they can submit to a repository and assist libraries in their

\footnotetext{
${ }^{6} 3$ Implementing this recommendation is likely to vary by institution. Some academic libraries have copyright attorneys that work within the library, or an established relationship between the institution's general counsel or DMCA agent and the library, making establishing the line of communication relatively simple. Many academic institutions have more limited resources, however, and may rely on outside counsel for copyright work, increasing the importance of establishing clear connections between library staff and counsel.
} 
notice-handling decisions. Publishers should take recent fair use case law into account when developing these policies in order to avoid targeting use that is non-infringing. ${ }^{64}$

- Publishers should ensure that REOs, if used, comply with publisher notice-sending policies. Publishers who work with REOs should clearly communicate their notice-sending policies to these services and should periodically review the organization's practices to verify that they are in compliance with such policies. Publishers should critically evaluate any automated notice-sending practices employed and should ensure that there are systems in place to increase notice accuracy and limit collateral damage.

- Academic libraries should consider creating educational materials about the counter notice process and tools that make it easy for authors whose works are challenged to send counter notices if their content is inappropriately targeted for take down. Libraries have long provided user copyright education. Expanding this to include tools to help repository authors consider whether a takedown notice targeting their works is correct, and to file a counter notice if it is not, would assist authors whose works are challenged. Providing information and tools may also help libraries consider the merits of notices, as authors are likely to have better information about publication and third-party content agreements, which they could communicate to the library and the notice sender through the tool.

\section{CONCLUSION}

Although academic libraries have historically received few formal DMCA takedown requests, recent notice-sending activity, coupled with the growth of open access policies and repositories, suggests that

\footnotetext{
${ }^{64}$ See, e.g., Google Inc., 804 F.3d 202; HathiTrust, 755 F.3d 87; Patton, 769 F.3d 1232.
} 
they may receive more DMCA requests as their online offerings grow. At the same time, libraries have a large amount of experience, and thus more comfort, with handling non-DMCA takedown requests.

As libraries continue to digitize collections and grow open access repositories, their long experience with less-formal requests and their relatively well-developed norms for handling those requests can serve as a foundation for handling the potential growth in DMCA notices. In addition, the growth itself might be curtailed if stakeholders take steps to limit the need to use the DMCA notice and takedown process. Educating authors about author-friendly publishing practices, continuing to push for institutional open access policies, and developing best practices for DMCA notice handling might all help. Deliberate effort from all stakeholders can help ensure that the notice and takedown system strikes a fair balance between academic libraries' needs to limit liability and fulfill their preservation and access missions and rightsholders' needs for an effective method for removing infringing content from library platforms. 


\section{APPENDIX A: NOTICE AND TAKEDOWN LIBRARY SURVEY}

Note: We are asking about copyright takedown notices-those sent under Section 512 of the United States DMCA or similar laws outside the U.S., along with any that simply make a copyright claim about library activity-even if that claim does not formally fall under 512's safe harbor provisions. We are also interested in any notices that appear to be about copyright, whether under 512 or not, even if they are really expressing a concern about something else, like privacy. We are not asking about government requests for data or removal.

1. What is your name and position?

2. What is the name of your institution?

3. Is it a private or public institution?

- Private

- Public

4. Is your institution a local library, university library, an archive, etc.?

5. Roughly how many employees does your institution have?

6. What types of services does your institution provide?

7. Does your institution serve, or has it previously served, as the recipient of takedown notices for a broader institution, such as a university?

- Yes, currently [please describe]

- Yes, in the past, but no longer [please describe]

- No

8. Do you engage in copyright educational efforts for your users?

- Yes, and we do this because we are a university following 512(e) (safe harbor for universities)

- Yes, we do this although we are not covered by 512(e)

- No, we do not

9. Please briefly describe any educational efforts (web outreach, classes, use a curriculum from an organization, etc.). 
10. About how much person-power do you employ in copyright educational efforts for your users? (e.g., 2.5 full-time positions' worth)

If you indicated your institution served or has served as the recipient of takedown notices for a broader institution, please answer the remaining questions only for notices sent regarding library or archive activities or services, if possible; we will follow up with a survey regarding notices to the broader institution.

11. Where are notices received (i.e. location of the office)?

- Country

- State and province

12. Approximately when did your institution start receiving copyright takedown notices? (Year and month if possible)

13. How many separate notices (which each may include multiple links or claims):

- Do you receive on average per month?

- Have you received so far in 2014?

- Did you receive in total in all of 2013?

14. Do you know or can you estimate the number of separate notices (which each may include multiple links or claims) received in:

- 2012

- 2011

- 2010

15. Do you know (or can you estimate) the total number of URLs or alleged infringements cited in these notices:

- 2014 (so far)

- 2013

- 2012

- 2011

- 2010

- Sorry, we can't determine this easily

16. How many of these notices were sent under a regime other than the U.S. DMCA (e.g., South Africa's similar regime):

- 2014 (so far)

- 2013

- 2012

- 2011

- 2010 
17. Which country or countries' laws are included in these notice submissions (e.g, Canada, China, South Africa)?

18. Has the number of notices you receive changed over time?

- Yes, overall increase

- Yes, overall decrease

- Yes, it ebbs and flows

- No / Cannot determine

19. If the number has changed, do you have any thoughts about why this has occurred?

20. Are there any repeat or typical senders? Have the types of senders changed over time?

21. Do any of your services (for example, an open access repository, an online collection, or other feature) attract a disproportionate number of notices?

22. Do you use a web form or a dedicated email form to receive takedown notices?

- Yes

- No

23. If yes, when did you introduce it?

24. If yes, has it had any obvious impact on the number or type of notices you receive? (e.g., More or fewer copyright notices? More or fewer automated notices? More or fewer junk notices?)

25. Does your institution deal with takedown notices directed to your services, or do they go somewhere else (e.g., to a general counsel's office, a city attorney, or an IT department)?

- Come directly to us and are processed by us

- Go to or are referred to another department for processing

26. If you indicated another department processes takedown notices, please describe how this is handled.

27. About how much person-power do you employ to review notices? (e.g., 2.5 full-time positions' worth) 
28. How many lawyer-positions does this number include? (e.g., 1 fulltime position, escalate to lawyer in general counsel's office when needed)

29. Is your process supplemented by automated filtering and/or notice processing of some kind?

- Yes, content filtering

- Yes, automated notice processing

- No

30. If yes, can you describe this system?

31. If yes, does this system ever escalate to human review?

- Yes

- No

32. If yes, please describe when escalation occurs:

33. How many counter notices did you receive in...

- 2014 (so far)

- 2013

- 2012

- 2011

- 2010

34. About what percentage of takedown requests result in:

- No action

- Content takedown

- Putback

- Has this changed over the past few years?

35. What are the most common non-copyright claims in "copyright" notices (e.g., privacy, defamation, complaints by a third party about material, etc.)?

36. Do you ever take down material in response to notices, when 512 does not require you to do so? (This could be because the claim is not actually a copyright claim, because you have no duty under 512 for the relevant material, or another reason)?

- Yes

- No

- Please Describe 
37. What are the most common bases for rejecting a takedown request?

38. What are the most common legitimate copyright complaints in takedown notices?

39. Can you tell us about your policies regarding users who are the subject of repeated takedown requests? Do you employ a "three strikes," "six strikes" or similar policy to deal with such situations? Or a "two strikes" policy in light of 512(e)? Do you terminate accounts for repeat takedown requests? If so, under what conditions?

40. If your institution is part of a university, do you know approximately what percent of takedown requests you receive are directed at activities of faculty and graduate students?

- Total

- For activity involving the provision of required or recommended instructional materials (taught by that faculty or graduate student at your university within the preceding 3 years)

- How often do these notices result in termination of user accounts?

41. Have upstream providers or another unit in your institution ever notified you that they received a takedown demand based on your services?

- Yes

- No

42. If yes, have they ever notified you of or taken any action against you (such as pulling your site down temporarily)?

43. Do you publicly report on your notice and takedown activities?

- Yes

- No

44. If no, why not?

45. What are the main benefits of the notice and takedown process under Section 512 ?

46. What are the main challenges or problems with the notice and takedown process under Section 512? 
47. Are there other issues around notice and takedown that you would like to emphasize or flag to us for research? Or any other comments you have?

48. Would you be willing to discuss sharing your institution's notices for research purposes?

- Yes

- No

49. Are there questions in this survey that you could not answer? Or do not wish to answer?

50. If so, we would appreciate knowing a bit more about why so that we can understand any hesitations and improve the survey.

51. If you're willing for us to follow up, please leave us your email address. 